tante y como hemos visto, dadas las comparaciones y semejanzas atribuimos estas obras a artistas del círculo o influencia de Alonso Berruguete, pues en todas ellas puede rastrearse la impronta genial de ese peculiar modo de hacer la figura humana utilizando un canon alargado, a menudo torsionando al extremo los cuerpos y realizando rostros desencajados y hasta violentos. Un estilo característico que representa como ningún otro el manierismo hispano, y que, por sí mismo y en sus múltiples seguidores y epígonos, marcará el camino a seguir por el realismo de la imaginería barroca española.

Pero si nuestras dos figuras de Profetas, por sus coincidencias con algunas del Facistol y Tenebrario sevillanos, así como con otras del retablo de Mondejar, e incluso con dibujos del Zúccaro, están en la línea más depurada de Juan Bautista Vázquez, la tercera, correspondiente al Apóstol, presenta una corporeidad y una energía que la acercan más al trabajo de otros artistas del foco toledano como los Velasco.

CARMEn Fernández AHIJAdo I.E.S. Leandro Fernández de Moratín (Guadalajara)

\title{
UNA REMUNERACIÓN NO CONVENCIONAL EN EL PAGO DE UN RETABLO TARDOGÓTICO NAVARRO
}

Desconocemos el lugar de nacimiento del pintor Diego Polo aunque no creemos que fuera la villa de Puente la Reina ${ }^{1}$. Sabemos que mantuvo en la citada villa su taller hasta su muerte ${ }^{2}$. Nuestra hipótesis es que el maestro Polo era originario de Aragón, donde debió formarse en el entorno del pintor Martín Bernat. Su llegada a Navarra pudo producirse como consecuencia de la asociación con el entallador maestro Terín. Tampoco sabemos su fecha de nacimiento pero intuimos que debía de estar cercana a la de su colaborador —entre 1460 y 1465 - ${ }^{3}$.

Debió instalar su taller en Puente la Reina a finales del siglo xv, momento en el que la villa decidió sustituir su vieja iglesia románica de Santiago por la actual — terminada a fines del siglo XVI— ${ }^{4}$, por esta razón Diego Polo no trabajó, que sepamos, para las parroquias - Santiago y San Pedro- de Puente la Reina ${ }^{5}$. Debió de ser feligrés de la parroquia de San Pedro de Puente la Reina, aspecto que basamos en la presencia de su vicario don Pedro de Sarría como testigo de su parte en el contrato de Legarda, en el que incluso - el citado clérigo- llega a firmar en nombre del maestro puesto que éste no sabía escribir ${ }^{6}$. En Puente la Reina casó

\footnotetext{
${ }^{1}$ Después de investigar en los archivos parroquiales de Santiago y San Pedro de Puente la Reina - libros de bautismos y defunciones-, no hemos encontrado noticias sobre el linaje de los Polo en la villa. Existe un reconocimiento de hidalguía a favor del apellido Polo, datado en Peralta en 1566 - J. M. De Huarte y de Jáuregui y J. de Rújula y de Ochotorena, Nobiliario del Reino de Navarra, Madrid, 1923, p. 433-, aunque no creemos que tenga demasiada relación con el maestro Diego Polo.

${ }^{2}$ En la querella por el retablo de San Juan Bautista de Obanos, al final de sus días, se menciona que Diego Polo era vecino de Puente la Reina - J. R. Castro Álava, Cuadernos de Arte Navarro, Pamplona, 1944, pp. 35-38-

${ }^{3}$ C. Fernández Ladreda, «Maestre Terín, un escultor activo en Navarra en torno al 1500», Actas del Congreso Internacional sobre Gil Siloe y la escultura de su época, Burgos, 2001, pp. 539-540.

4 J. M. Jimeno Jurio, «Puente la Reina. Iglesia de Santiago. Del Románico al Renacimiento», Príncipe de Viana, ${ }^{\circ} 218$, Pamplona, 1999. Al concluirse las obras de la parroquia a finales del siglo xvı, los muebles litúrgicos comenzaron a realizarse a partir del siglo xviI, obviamente, en estilo Barroco.

5 Además de la reseña sobre la parroquia de Santiago debemos considerar que la parroquia de San Pedro, de la misma villa - de la que seguramente Diego Polo era feligrés - era una iglesia pequeña - de una sola nave- que sería totalmente reformada en el siglo xviII merced al legado del indiano Miguel Francisco de Gambarte — G. García Gaínza y otros, $C a$ tálogo..., vol. $\mathrm{V}^{* *}$, pp. 526-532-.

6 J. R. Castro Álava, Cuadernos..., p. 43.

$A E A$, LXXVIII, 2005, 310, pp. 175 a 201
} 

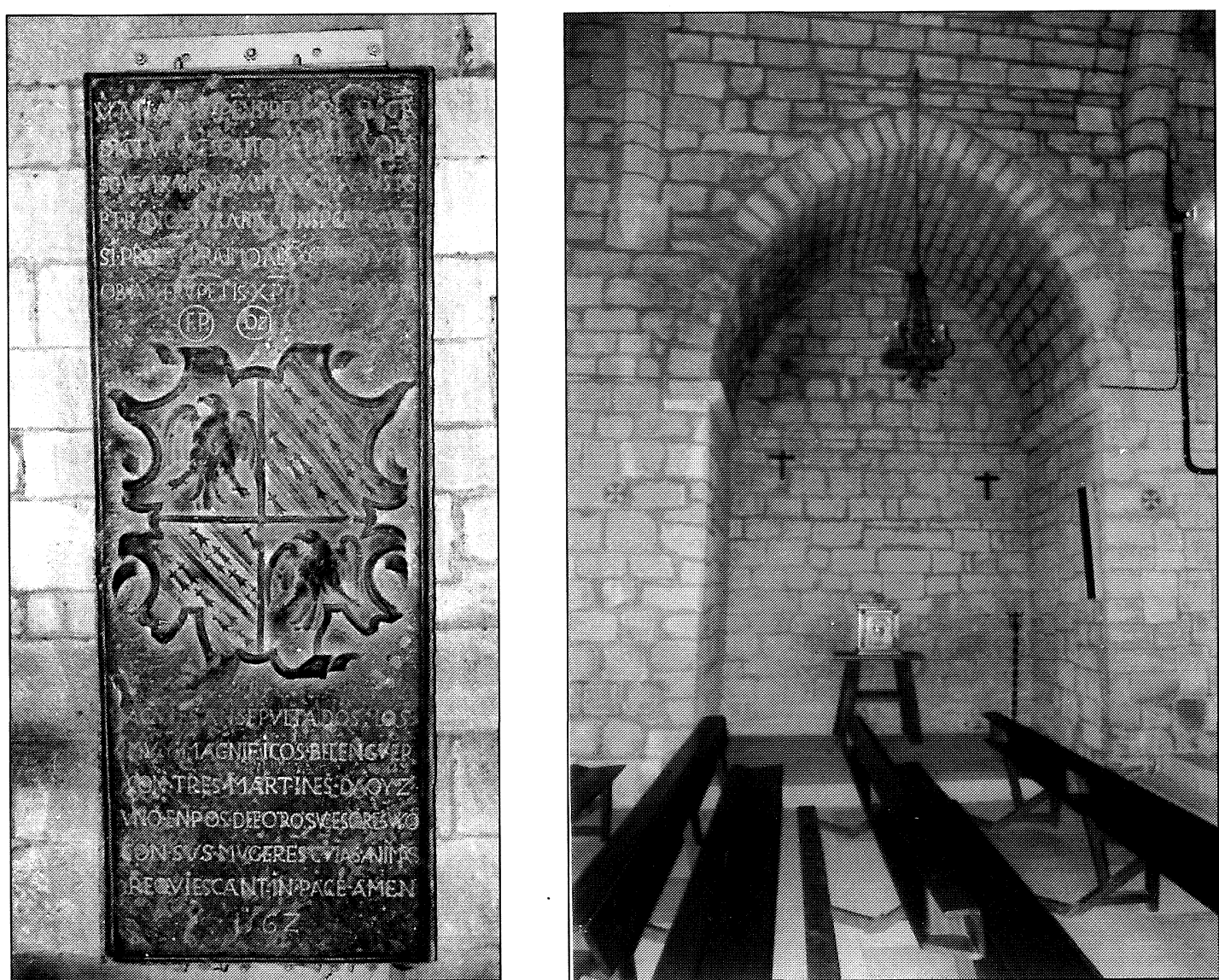

Fig. 1. Lápida de la Familia Aoiz. Realizada por Belenguer de Aoiz, cuñado del pintor Diego Polo, en 1562 para el sepulcro familiar de la capilla de Santa Lucía (Iglesia del Crucifijo, Puente la Reina, Navarra).

Fig. 2. Aspecto actual de la capilla de Santa Lucía en la Iglesia del Crucifijo. Puente la Reina Navarra.

- a finales del siglo xv- con Juana de Aoiz con la que tuvo cuatro hijos: Ana —nacida en 1518 y casada con el comerciante pamplonés Juan de Lerga—, María Juana —nacida en 1516 y casada con el puentesino Domingo Garde—, Marina y Martín —nacido hacia 1498 y casado con María Andueza y Arano, con la que tuvo tres hijos y una hija- ${ }^{7}$. El maestro Polo falleció en Puente la Reina, al igual que su esposa, en $1531^{8}$.

La primera obra conocida de Diego Polo, hoy desaparecida, es el retablo de Santa Lucía de la Iglesia del Crucifijo de Puente la Reina, convenido con los frailes sanjuanistas - comendatarios de la iglesia- el 18 de diciembre de $1501^{9}$. «Sepan cuantos esta carta verán et hoirán que estos son los tratos, convenios e composiciones fechos e firmados entre los muy venerables e devotos religiosos, fray Martín de Leach, prior de la yglesia e monasterio del crucifixo del cabo de la villa de Puent de la Reyna, fray Carlos de Ayanz, fray Juan de Orendain, fray Salvador de Orcoyen, fray Pedro de Aoiz e fray Pedro de Biurrun, frayles conventuales de la yglesia y monasterio del Crucifixo, plegados a capitol dentro de la dicha yglesia del Crucifixo a toque de campana, segunt que asta aqui en tales e semejantes actos e negocios han usado e acostumbrado, de la una parte y el honorable maestro Diego Polo, pintor, vecino y morador

\footnotetext{
7 Archivo General de Navarra. $\mathrm{n}^{\circ}$ 95259, testamento de maese Diego Polo, 8-X-1531.

8 Archivo General de Navarra. Proceso $n^{\circ}$ 97664. Proceso de Martín de Polo y Aoiz contra Nicolás de Andueza, su suegro, por una dote.

${ }^{9}$ Archivo General de Navarra. Proceso ${ }^{\circ} 95259$.
} 
de la dicha villa de Puent (...) Todo esto fue hecho dentro de la yglesia del Crucifixo deciocheno dia del mes de diciembre del año del nascimiento de Nuestro Señor Jesucristo de mil quinientos e uno, de todo lo sobredicho es, son testigos, qui clamados e rogados presentes fueron e qui por tales testigos se otorgaron ser nombradament los honrrados e discreptos señores Joan de Heneriz e Joan de Labayen, vecinos e moradores en la dicha villa de la Puent. Notario Martín de Brun».

El mencionado retablo debía terminarse en un año a partir de la fecha de contrato «bien adornado, ricamente cumplido, segunt a semblantes pertenece esta part del dia e fiesta de Pascua de Navidat primero veniente en un año», se ajustaría a las medidas de la capilla para el que estaba destinado y llevaría las iconografías de Santa Lucía, San Lorenzo y San Jorge. Pero lo más interesante del contrato - aspecto único en Navarra- es que Polo debería realizar el retablo a su costa y el pago por tal obra sería el derecho a realizar dos o tres tumbas al pie del mismo para él, su esposa y descendientes. «...en tal manera que el dicho maestre Diego prometió e hubo en convenio de facer e pintar a sus propias espensas un retablo de diez a once palmos de largo y tanto cuanto es menester de ancho para la capilla de Sacta Lucía de la dicha yglesia del Crucifixo para en servicio de Dios Nuestro Señor y honra de la dicha yglesia del Crucifixo e aumento de la devoción, que hay en la dicha capilla e abrá de Nuestra Señora Sacta Lucia, Sant Jorge et Sant Lorenz (...) E assi los dichos señores prior e frailes, capitol, juntamente sin vareamiento alguno en remuneración de las dichas obras e cosas pias ficieron gracia e merced a los dichos maestre Diego e a su esposa Joana de Aoiz e a sus decendientes dellos de la dicha capilla de Sacta Lucia para que puedan e hayan de facer dos o tres sepulturas e las que pudieran facer dentro de la dicha capilla en tal manera e con tal condicion que ninguna ni alguna persona e personas no se puedan sepellir o enterrar dentro de la dicha capilla, llamada de Sacta Lucia, si no que sea con licencia, permiso e consentimiento de los dichos maestre Diego Polo e Joana de Aoiz su esposa e sus descendientes, pero si caso que los dichos prior y frailes de la dicha yglesia e monasterio del Crucifixo quisieran alargar la dicha capilla, sacando la paret del costado mas afuera e facer alguna obra la puedan facer no perjudicanto en tanto y quanto aya seido dado a los dichos maestre Diego e asu mujer e descendientes dellos».

Tan insólita remuneración debe explicarse seguramente por el origen hidalgo de su esposa, que era hermana de Belenguer de Aoiz - alto funcionario de la moneda en Navarra y Residente en Pamplona- ${ }^{10}$. Ya en el mismo contrato, apreciamos que uno de los frailes que actúan como comitentes se llama Pedro de Aoiz, lo que nos puede indicar un parentesco con la esposa del pintor. Seguramente la sepultura terminó convirtiéndose en propia de los Aoiz, de tal manera que en la actualidad vemos en la iglesia del Crucifijo de Puente la Reina una gran lápida sepulcral con fecha de 1562 - veintinueve años después de la muerte de Diego Poloy con la siguiente inscripción: «AQVI ESTAN SEPULTADOS LOS MUY MAGNÍFICOS BELENGUER CON TRES MARTINES DE AOIZ UNO EN POS DE LOS OTROS SUCESORES SUYOS CON SUS MUJERES CUYAS ANIMAS REQUIESCANT IN PACE AMEN» (Fig. 1). En nuestra opinión el Belenguer mencionado en la lápida puentesina sería el cuñado de Diego Polo, cuyos hijos - los del primero-, Juan, Esteban, Belenguer — caballero de la orden de San Juan de Jerusalén y residente en Malta - y Francisca solicitan, en 1572, que se les reconozca la ejecutoría de hidalguía conseguida por su padre Belenguer de Aoiz ${ }^{11}$. En la mis-

\footnotetext{
${ }^{10}$ Archivo General de Navarra. Proceso no 97664. En el proceso entre Martín Polo y Aoiz — hijo del pintor- y Nicolás de Andueza - suegro del anterior - por la dote de la hija del segundo - María de Andueza- que había de casarse «rápidamente» con el citado Martín Polo y Aoiz, actúa como mediador, en 1533, Belenguer de Aoiz — tío de Martín y cuñado del pintor-.

11 J. M. Huarte y Jáuregui y J. Rújula y Ochotorena, Nobiliario..., vol. II, p. 377.
}

AEA, LXXVIII, 2005, 310, pp. 175 a 201 
ma losa sepulcral se encuentra el escudo de los Aoiz: $1^{\circ}$ y $4^{\circ}$ cuartos de oro con águila de sable y $2^{\circ}$ y $3^{\circ}$ de plata con tres bandas de gules cargadas de una cotiza de oro, acostadas de armiños ${ }^{12}$. En resumen, las primitivas sepulturas del maestro Polo y su esposa en la capilla de Santa Lucía del Crucifijo - 1533 - se fueron transformando en una capilla sepulcral de los Aoiz donde permanecieron los restos de varias generaciones hasta la restauración de la iglesia en 1950, cuando la lápida sepulcral fue colocada en el muro del fondo de la nave del Crucifijo de la misma iglesia y los restos —entre los que estarían los del maestro Polo-, enterrados conjuntamente debajo del actual coro ${ }^{13}$. La capilla de Santa Lucía (Fig. 2) estaba situada en la nave gótica de la iglesia del Crucifijo de Puente la Reina - donde hoy se encuentra el Sagrario-, deducción que hacemos a la luz del testimonio de Cristóbal de Hurtubia que, en 1570, en un proceso ${ }^{14}$ abierto por los Aoiz contra los frailes del Crucifijo - a raíz de la actuación de éstos que, recelando de la influencia de la familia Aoiz en su iglesia, rompieron algunos escudos, destrozaron inscripciones, cambiaron la llave de la reja de entrada y propusieron que el retablo de Santa Lucía fuera trasladado a la iglesia de los Trinitarios de la misma villa- declara: «la capilla e retablo de Santa Lucia está en entrando en el dicho monasterio de cara a mano izquierda en la nabada del Santo Crucifixo con su rexado y puerta de fusta ${ }^{15}$ ». En el mismo proceso declara don Juan de Elordi clérigo beneficiado de la parroquial de San Pedro de Puente, quien nos describe una de las inscripciones destrozadas por los Sanjuanistas que no dejan lugar a dudas sobre la propiedad de la citada capilla: «Solía estar escrito un letrero de letra grande en el aro alto del rexado de fusta de la dicha capilla y en el decía estas palabras ESTA CAPILLA ES DE MAESTRE DIEGO POLO Y DE JOANA DE AOIZ SU MUJER Y DE SUS DESCENDIENTES FECHA EN EL AÑO DE MIL QUINIENTOS $E U N O »$. Por último, el mismo sacerdote, que dice tener 65 años en 1570, recuerda que la talla de Santa Lucía fue realizada por «el mastre Tarín en Estella». Esta última información nos indica que el retablo era mixto, de talla y pintura, nos habla de un posible taller del maestro Terín en Estella y, por supuesto, pone en relación a Diego Polo con el maestro Terín en la fecha mas temprana conocida hasta ahora ${ }^{16}$.

Alberto J. Aceldegui Apesteguía Universidad de Navarra. Pamplona

\footnotetext{
12 F. Menéndez Pidal y J. J. Martinena Ruiz, Libro de Armería del Reino de Pamplona, Pamplona, 2001, p. 224 y fig. $\mathrm{n}^{\circ}$ 81-4 y A. y A. García Carraffa, Enciclopedia heráldica y genealógica hispano-americana, vol. VII, Madrid, 1958, pp. 179-180.

${ }_{13}$ Estos datos se los agradezco a D. Javier López Andoño, sacerdote Dehoniano que estuvo presente durante las obras y a D. Rafael Carasatorre Vidaurre.

14 Archivo General de Navarra. Proceso $n^{\circ} 28050$.

15 Archivo General de Navarra. Proceso 28050, folio 4.

16 Véase nota número 3.
} 